\title{
Methanol oxidation over copper supported catalysts.
}

\author{
L. Leke ${ }^{1,3 *}$; O A. Olawuyi ${ }^{4}$; S. O Okopi ${ }^{3}$; T T Weor ${ }^{3}$; R. P.K. Wells ${ }^{1} \&$ J. A. Anderson ${ }^{1,2}$ \\ ${ }^{1}$ Surface Chemistry and Catalysis Group, Department of Chemistry, University of Aberdeen, AB24 3UE, UK \\ ${ }^{2}$ Materials and Chemical Engineering Group, School of Engineering, University of Aberdeen, AB24 3UE, UK \\ ${ }^{3}$ Chemistry Department, Faculty of Science, Benue State University, PMB 102119, Makurdi, Benue State \\ ${ }^{4}$ Nigeria Defence Academy, Kaduna State, Nigeria \\ *Correspondents Author: l.leke@bsum.edu.ng, +234-803-705-8236 \\ Received 09 August 2020; accepted 28 August 2020, published online 04 September 2020
}

\begin{abstract}
Oxidation of methanol has been studied over a range of temperature and contact times with a synthesised, $1 \mathrm{wt} \%$ copper catalysts supported over $\mathrm{Al}_{2} \mathrm{O}_{3}$ and $\mathrm{SiO}_{2}$. Characterisation of these catalysts was performed by nitrogen adsorption and porosity measurements (BET), X-Ray Diffraction (XRD), and IR spectroscopy of adsorbed CO. BET measurement revealed surface areas reducing from 105 to $104 \mathrm{~m}^{2} \mathrm{~g}^{-1}$ for pure alumina to copper supported catalyst while the silica ones reduced from 247 to $240 \mathrm{~m}^{2} \mathrm{~g}^{-1}$ for pure silica to the copper supported respectively. Pore sizes also reduced from $32-23 \mathrm{~nm}$ and $23-20.3 \mathrm{~nm}$ for the alumina and silica catalysts respectively. No crystalline phases from the diffraction patterns of the loaded metals were found to be present on the XRD. CO adsorption studies showed the presence of small cluster metal atoms adsorbed on the surface of the catalysts with Temperature Programmed Reduction (TPR) experiments revealing the presence of partially oxidised and well dispersed $\mathrm{Cu}$ atoms. The alumina supported catalyst were more active than the silica ones while for selectivity and yield for formaldehyde, the reverse was the case. The alumina supported significantly showed high yields of Dimethyl ether (DME) while the silica showed high yield for methyl formate (MF) with $\mathrm{CO}_{\mathrm{x}}$ and $\mathrm{CH}_{4}$ detected in very small quantities.
\end{abstract}

Keywords: methanol, oxidation, supported, oxidation, copper, catalyst 


\section{Introduction}

Efficient catalysts have been synthesised over the years for possible good selectivity for the oxidation of alcohols to the corresponding carbonyl compounds [1]. Consequently, various catalysts have been synthesised to this effect [2] and investigations to understand their reaction pathways have also been made [3]. Methanol oxidation is mainly performed catalytically and precedes either through the partial or total oxidation paths. The partial path produces a variety of compounds while the total oxidation path leads to the production of COx with formaldehyde being the most prominent [3]. These products are a consequence of various conditions including the type of site, the intermediate formed on the catalyst site and the reaction condition (e.g. temperature and partial pressure of the reactants, contact time/gas hourly space velocity). In this process, methanol molecules are proposed to either adsorb wholly or dissociatively on the catalyst [4-6]. The two main processes that take place during the course of this oxidation reaction either in parallel or simultaneously are oxidation and dehydrogenation [5]. During the oxidation of methanol, there are various processes that can possibly take place. These can take place simultaneously or consecutively. These processes include; selective/partial oxidation, dehydrogenation and total oxidation/combustion [5].

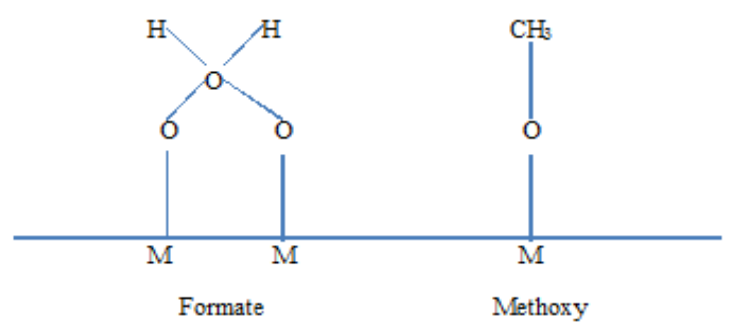

Figure 1: A schematic diagram showing the adsorption of the formate and methoxy species unto a catalyst surface

Total oxidation/ combustion

$\mathrm{CH}_{3} \mathrm{OH}+3 / 2 \mathrm{O}_{2} \rightarrow \mathrm{CO}_{2}+\mathrm{H}_{2} \mathrm{O} \ldots . . \Delta \mathrm{H} \mathrm{o}=-393 \mathrm{kJmol} \mathrm{l}^{-1}$

Selective/partial oxidation;

$\mathrm{CH}_{3} \mathrm{OH}+0.5 \mathrm{O}_{2} \rightarrow \mathrm{CH}_{2} \mathrm{O}+\mathrm{H}_{2} \mathrm{O} \ldots . . \Delta \mathrm{Ho}=-157 \mathrm{kJmol}^{-1}$

Dehydrogenation

$\mathrm{CH}_{3} \mathrm{OH} \rightarrow \mathrm{CH}_{2} \mathrm{O}+\mathrm{H}_{2} \ldots \mathrm{\Delta H} 0=+84 \mathrm{kJmol}^{-1}$

From the above, the combustion pathway with the formation of total oxidation products $\left(\mathrm{CO}_{2}\right)$ and $\left(\mathrm{H}_{2} \mathrm{O}\right)$ are thermodynamically favoured compared to formaldehyde formation pathway.

The popular production process for formaldehyde is air oxidation of methanol. This has been reported to be an exothermic reaction at atmospheric pressure and in the temperature range $300-400{ }^{\circ} \mathrm{C}$ [8]. All industrial production of formaldehyde use air to oxidise methanol. Air is preferred as an oxidant for this reaction, for economic reasons, and since the use of organic oxidants poses environmental problems of which there are strict environmental laws [3]. When a catalyst is employed in this process, there are a variety of processes that are possible, within the thermodynamic and kinetic boundaries for the formation of different products. Other conditions of reaction also have marked influence on the process. For instance, in the silver-catalysed process, a higher methanol/air ratio favours the production of formaldehyde, while for the other metal oxide catalysts; the reverse is true in order to obtain similar results. In this research, some $1 \mathrm{wt} \% \mathrm{Cu}$ supported on both silica and alumina supports (Silica as a support for heterogeneous catalysts was employed to provide good thermal stability, fairly chemical inertness and surface areas, while alumina was used offers similar properties but with slightly higher acidity) were synthesised, these catalysts were used to investigate the methanol oxidation reaction to study the product distributions under the different reaction conditions. 


\section{Experimental}

\section{Preparation of catalysts}

While considering a method of supported catalyst preparation, the fine dispersion of the metal particles in the pores of the support is of paramount importance [9]. The conventional impregnation method where the support is impregnated with a solution of the salt of the target metal oxide $[10,11]$ was used. The preparation of similar catalysts at low metal loading gave the desired properties after characterisation.

These supports were impregnated with the metal salts under investigation. The active metals were loaded onto the various supports as described below.

The $1 \mathrm{wt} \% \mathrm{Cu} / \mathrm{Al}_{2} \mathrm{O}_{3}, \mathrm{Cu} / \mathrm{SiO}_{2}$, catalysts were prepared simply by the wet impregnation of the various supports with their respective salts to obtain the desired catalyst in the right quantity as described below.

For a target weight of $10 \mathrm{~g}$ of catalyst $\left(1 \mathrm{wt} . \% \mathrm{Cu} / \mathrm{Al}_{2} \mathrm{O}_{3}\right), 0.380 \mathrm{~g}$ of $\mathrm{Cu}\left(\mathrm{NO}_{3}\right)_{2} \cdot 3 \mathrm{H}_{2} \mathrm{O}(\mathrm{BDH})$ was weighed and added to distilled water containing $9.900 \mathrm{~g} \gamma-\mathrm{Al}_{2} \mathrm{O}_{3}$ (Degussa) in a beaker. This was stirred on a heating/stirring mantle at $<80{ }^{\circ} \mathrm{C}$ until a thick slurry was formed. The beaker content was then further dried more gradually at lower temperatures overnight. This was then ground into finer powder and further dried in at temperatures $<60{ }^{\circ} \mathrm{C}$. Then grinding was performed in a $30-60$ min interval until a fine dried powder was formed. Calcination of the produced catalyst was carried out using parameters used by Kaichev et al. [12] where the catalyst was calcined at $400{ }^{\circ} \mathrm{C}$ for $4 \mathrm{~h}$. Calcination was carried out by placing the catalyst samples prepared as stated above in a porous tubular quartz glass, which was placed in a calcination unit containing a furnace. Air was flowed through the tube containing the catalysts at a 50 $\mathrm{ml} . \mathrm{min}^{-1}$ flow rate with the furnace temperature ramped $10{ }^{\circ} \mathrm{Cmin}^{-1}$.

\section{Characterisation of catalysts}

\section{Nitrogen adsorption studies.}

These experiments were conducted on a Micromeritics Tristar 3000 V4.02 surface area and pore volume analyser instrument where $0.15-0.20 \mathrm{~g}$ sample catalysts were and pre-treated by outgassing at $200{ }^{\circ} \mathrm{C}$ for $3 \mathrm{~h}$. The surface analyses of the samples were measured and calculated using the BET and BJH methods at liquid nitrogen temperature and normalized per gram of each sample. The BET method employed for the measurement of surface area uses $\mathrm{N}_{2}$ as the adsorptive at its liquefying temperature $\left(-195^{\circ} \mathrm{C}\right)$ assuming the BET monolayer is closely packed, giving average area of $\mathrm{N}_{2}$ to be $0.162 \mathrm{~nm}^{2}$ [10].

\section{CO adsorption}

The catalysts were pressed into $\sim 16 \mathrm{~mm}$ discs and suspended in a $\mathrm{CaF}_{2} \mathrm{IR}$ cell attached to a vacuum line set-up. The discs were pre-treated by in-situ calcination or reduction, cooled and contacted with different pressures of $\mathrm{CO}$ as stated in each case presented in the results. The carbonyl region of the IR bands was distinguished from the gas phase $\mathrm{CO}$ contribution in case of overlaps by gaseous $\mathrm{CO}$ evacuation by the vacuum pump. The $\mathrm{CO}$ adsorption was carried out using the reaction procedure of the FTIR set-up mentioned above. This gave spectra of $\mathrm{CO}$ adsorbed on the metals which were measured over a range of $2000-2500 \mathrm{~cm}^{-1}$ with a resolution of $4 \mathrm{~cm}^{-1}$ after 150 scans, after scanning the background and the software automatically ratioing the background and sample signals.

\section{Temperature-programmed reduction (T P R)}

TPR experiments were conducted using a TPDRO 1100 Thermo-Quest CE Instruments. About $0.250 \mathrm{~g}$ of the copper catalyst was weighed into a quartz reactor sample holder held between quartz wool plugs and loaded unto the instrument. A reducing gas mixture, $5 \% \mathrm{H}$ diluted in $\mathrm{He}$ was flown over the sample under programmed conditions of temperature and flow rate of the reducing mixture gas. A thermal conductivity detector (TCD) recorded changes in the thermal conductivity of the gas stream. The TCD signal was then converted to concentration of active gas using a calibration factor and presented as a spectrum where the peak maxima indicate the temperature that corresponds to the maximum rate of reduction. The instrument was programmed to carry out a reduction on the catalysts from $40-800{ }^{\circ} \mathrm{C}$ with a flow rate of the reducing gas at $20 \mathrm{ml} / \mathrm{min}$ at a heating rate of $10^{\circ} \mathrm{C} / \mathrm{min}$. A Thermo Finnigan version 2.0 release 0.1 software which presents the result as TCD signal ( $\mathrm{mV}$ or $\mathrm{mV} / \mathrm{g})$, oven and sample temperatures versus time was used to process the data accordingly. 


\section{X-Ray Diffraction (X R D)}

Phase identification and crystallinity studies were carried out, with the aid of Bruker-AXS model X-ray diffractometer with $\mathrm{Cu} \mathrm{k} \alpha$ monochromatic radiation $(0.15418 \mathrm{~nm}$ wavelength). Measurements were performed at $22{ }^{\circ} \mathrm{C}$ with steps of $0.02{ }^{\circ}$ of $2 \theta$ range of $5-70^{\circ}$ and $2.5 \mathrm{~s} / \mathrm{step}$. Phase identifications from the diffraction patterns obtained from the results received were performed with the aid of a program developed in the Bruker-D8 software stored in a PC connected to the spectrometer.

\section{Catalytic activity studies}

\section{Catalyst testing}

The catalytic experiments were carried out in a fixed-bed tubular quartz reactor and a fitted analyser HP 5860 series Gas Chromatograph coupled with a HP FFAB (cross-linked FFAB) capillary column $(30.0 \mathrm{~mm} \times 0.32 \mathrm{~mm} \times 25 \mu \mathrm{m})$ with a maximum temperature $250^{\circ} \mathrm{C}$, coupled with an FID and an attached mass spectrometer, EcoSys-P Field Portable Mass Spectrometer.

Methanol oxidation was carried out at; $250,290,350$ and $400{ }^{\circ} \mathrm{C}$. A given amount of catalyst was diluted with $0.2-0.25 \mathrm{~g}$ inert phase SiC. The molar flow ratio (methanol / air) was varied in some reactions to probe it's effect. The residence times was between $0.195-2.166 \mathrm{~s}$ respectively by varying the diluent gas flow rate or the amount of catalysts. Products from this reaction were analysed online on the GC using the parameters stated on Table 1

Table 1: GC conditions for analysing products from the oxidation of methanol

\begin{tabular}{lll}
\hline PARAMETER & VALUE \\
\hline Injector temperature & $60 \mathrm{C}$ \\
Oven temperature & $30{ }^{\circ} \mathrm{C}$ isothermal & \\
Column & HP-FFAP (crosslinked $\quad$ FFAP) $30 \mathrm{~m} \quad \mathrm{x}$ \\
& $0.32 \mathrm{~mm} \times 25 \mu \mathrm{m}$. \\
Carrier gas flow rate & $\mathrm{N}_{2}, 0.2 \mathrm{~mL} / \mathrm{min}$ \\
Detector temperature & $240{ }^{\circ} \mathrm{C}$ \\
Detector gas & $\mathrm{H}_{2}$ and air
\end{tabular}

\section{Results}

\section{Nitrogen adsorption/desorption studies}

The textural properties of the catalysts used such as surface area, pore volume and pore size distribution were obtained from the $\mathrm{N}_{2}$ adsorption-desorption isotherms. The specific surface areas calculated using the Brunauer-Emmett-Teller (BET) method and the pore size and volume information were calculated from the desorption branch of the isotherms using Barrett-Joyner-Halenda method (BJH) ) are as presented in Figure 2 and Figure 3 with Table 2 showing a summary of the other parameters extrapolated

\section{Alumina Supported catalyst}

For the alumina supported materials, Figure 2, the nitrogen adsorption/ desorption isotherms corresponds to the type IV of the IUPAC classification [13] and exhibits hysteresis loop $\mathrm{H} 1$ and $\mathrm{H} 3$ also according to the IUPAC classification, extrapolated from the desorption route employing the BJH method calculated from the Kelvin equation. A slight decrease in the surface area of the catalyst was also observed on loading the active metal from $105 \mathrm{~m}^{2} \mathrm{~g}^{-1}$ for the pure alumina to 104 , for the supported catalyst. The pore sizes reduced from $32 \mathrm{~nm}$ for the pure silica to $23 \mathrm{~nm}$ for the copper supported catalyst. 

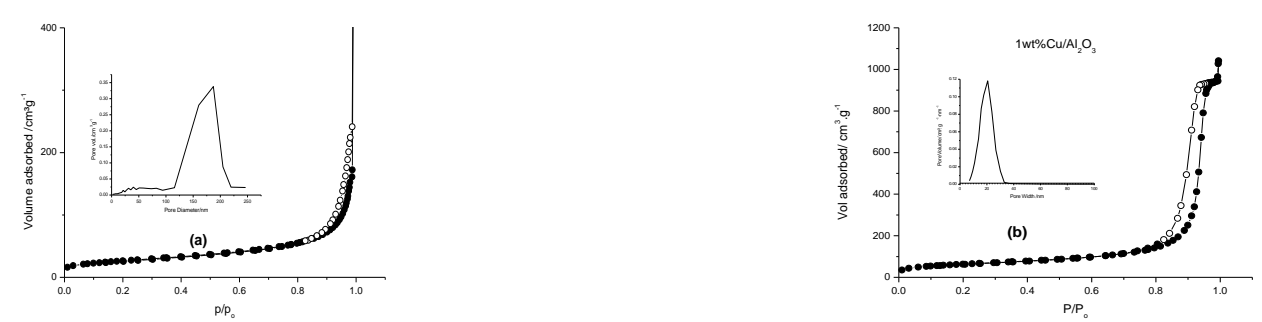

Figure 2: $\mathrm{N}_{2}$ adsorption isotherms with inserted $\mathrm{BJH}$ pore volume distributions of $(a)$ pure $\mathrm{Al}_{2} \mathrm{O}_{3}(b)$ $1 w t \% \mathrm{Cu} / \mathrm{Al}_{2} \mathrm{O}_{3}$
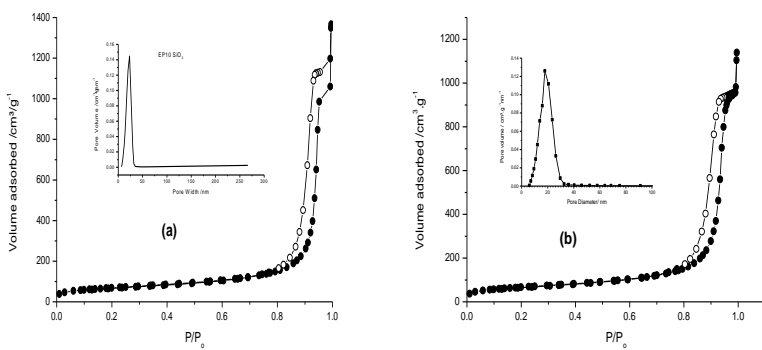

Figure 3: $\mathrm{N}_{2}$ adsorption isotherms with inserted $\mathrm{BJH}$ pore volume distributions of (a) pure $\mathrm{SiO}_{2}(b) 1$ wt\% $\mathrm{Cu} / \mathrm{SiO}_{2}$

\section{Silica supported catalysts}

The silica supported samples exhibited similar trends in the surface area with metal loading similar to that observed on the alumina supported materials. The nitrogen adsorption/desorption isotherms also correspond to the type IV of the IUPAC classification [13] and exhibit similar hysteresis loops as those observed for the alumina based materials. The surface area of the pure silica was measured to be $247 \mathrm{~m}^{2} \mathrm{~g}$ ${ }^{1}$ and decreased to 240 , for the silica supported catalyst. The pore sizes reduced from $23 \mathrm{~nm}$ for the pure silica to $20 \mathrm{~nm}$

Surface densities of the various metals on the catalyst surfaces were also calculated. The copper loaded samples appear to exhibit a higher surface density as compared to the silver ones. The silica supported catalysts show a lower metal density as compared to those based on alumina

Table 2: Results of the $\mathrm{N}_{2}$ studies characterisation of the catalysts

\begin{tabular}{lllll}
\hline Catalyst & Surface area/ $\mathbf{~ m}^{2} \mathbf{g}^{-1}$ & $\begin{array}{l}\text { BJH Pore Vol. } \\
/ \mathbf{c m}^{3} \mathbf{g}^{-1}\end{array}$ & Pore Diameter/nm & $\begin{array}{l}\text { Metal Surface } \\
\text { Density / atom } \mathbf{~ m}^{-2}\end{array}$ \\
\hline $1 \mathrm{wt} \% \mathrm{Cu} / \mathrm{Al}_{2} \mathrm{O}_{3}$ & 104 & 0.9 & 23 & 0.771 \\
$1 \mathrm{wt} \% \mathrm{Cu} / \mathrm{SiO}_{2}$ & 240 & 1.7 & 20.3 & 0.315 \\
& & & & - \\
Pure $\Upsilon-\mathrm{Al}_{2} \mathrm{O}_{3}$ & 105 & 1.5 & 32 & - \\
& & & & \\
\hline
\end{tabular}

Surface densities of the various metals on the catalyst surfaces were calculated using formulae from references $[14,15]$. 


\section{Power X-Ray Diffraction}

The XRD patterns of the catalysts used in this study together with their supports are presented in Figure 4 and Figure 5 for the alumina and the silica based catalysts respectively.

The alumina mono-metal supported catalysts show patterns that correspond to the patterns of $\gamma$-alumina only [16] while the silica based catalysts were amorphous to XRD analysis; showing no crystalline phases, where there was clearly the absence of diffraction patterns that are characteristic of the loaded metals or their oxides nor the support.
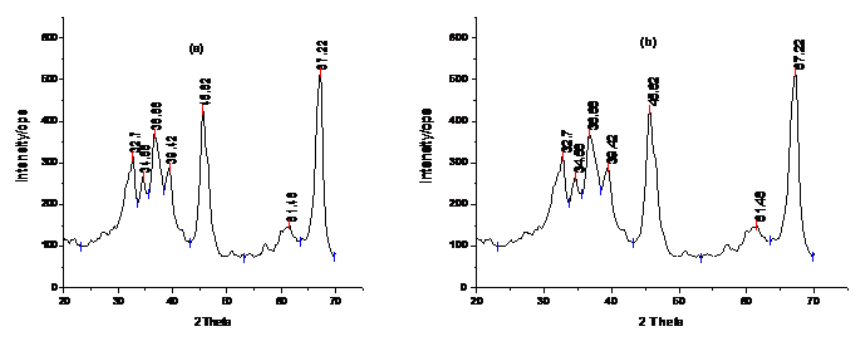

Figure 4: XRD patterns of the (a) pure $\mathrm{Al}_{2} \mathrm{O}_{3}(b) 1 w t \% \mathrm{Cu} / \mathrm{Al}_{2} \mathrm{O}_{3}$ catalysts

For the silica supported samples, no reflexions were observed on the XRD patterns presented in Figure 5 (a) and (b).
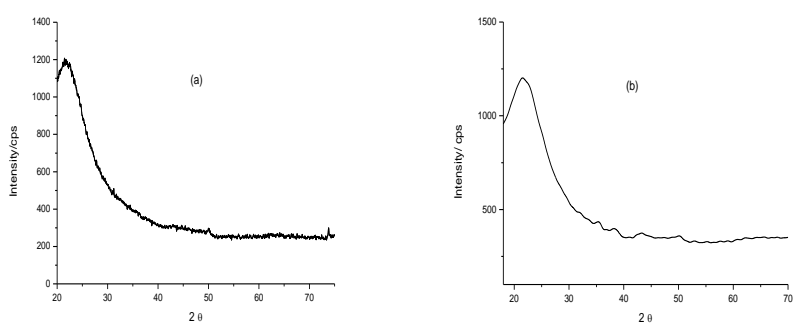

Figure 5: XRD patterns of the (a) pure $\mathrm{SiO}_{2}$ (b) $1 \mathrm{wt} \% \mathrm{Cu} / \mathrm{SiO}_{2}$ catalyst

An accepted explanation for such an observation in the literature has it that the loaded metals may likely be too amorphous or well dispersed on the surface of the support in the form of small clusters which are likely not detectable by the XRD technique [17-19] or due to the formation of finely dispersed species of the metals loaded which are also suggested not to be detectable by the technique [20]. These assumptions can as well be supported by characterisation with other techniques like TPR (presented and discussed further on)

\section{Temperature programmed reduction experiments}

Figure 6 shows the reduction profiles of $1 \mathrm{wt} \% \mathrm{Cu} / \mathrm{Al}_{2} \mathrm{O}_{3}$ and $\mathrm{Cu} / \mathrm{SiO}_{2}$, samples. Two unresolved signals were observed for the $1 \mathrm{wt} \% \mathrm{Cu} / \mathrm{Al}_{2} \mathrm{O}_{3}$, one centred around $267{ }^{\circ} \mathrm{C}$ and a shoulder at $297{ }^{\circ} \mathrm{C}$. The signal centred around $267{ }^{\circ} \mathrm{C}$ is attributed to highly dispersed $\mathrm{Cu}$ species [21] which is reported to weakly interact with the support on the surface of the alumina [22] whilst the $297{ }^{\circ} \mathrm{C}$ shoulder is attributed to the reduction of $\mathrm{Cu}$ species contained within slightly larger three-dimensional clusters. In addition, a very broad and weak/ non-intense signal centred on $717^{\circ} \mathrm{C}$ was observed and is characteristic of larger clusters of $\mathrm{CuO}[21]$ or possibly due to the reduction of aluminium oxides from the support of these samples.
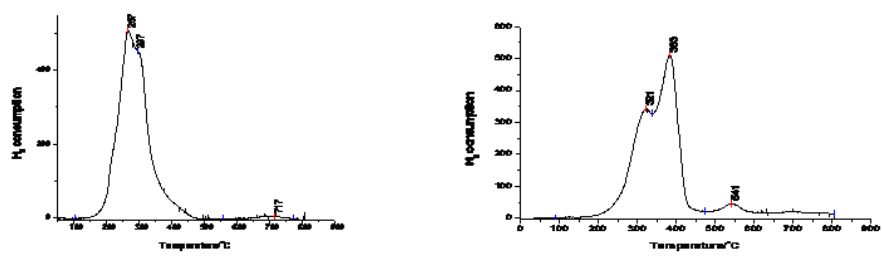

Figure 6: TPR profile of $1 \mathrm{wt} \% \mathrm{Cu} / \mathrm{Al}_{2} \mathrm{O}_{3}$ and $1 \mathrm{wt} \% \mathrm{Cu} / \mathrm{SiO}_{2}$ respectively 
The $\mathrm{Cu} / \mathrm{SiO}_{2}$ displays similar characteristics with the addition of a signal centred on $542{ }^{\circ} \mathrm{C}$. The two lower reduced signals centred at around 321 and $383^{\circ} \mathrm{C}$, are due to the reduction of highly dispersed $\mathrm{Cu}$ and small $\mathrm{CuO}$ clusters, respectively. The additional signal is typical of larger cluster $\mathrm{Cu}$ species which are characteristic at higher reduction temperature as compared to smaller and well dispersed clustered species. From the intensities of these signals, it can be confirmed that the main copper species present at the surface are the highly dispersed and small cluster $\mathrm{Cu}$ species. This is similar with trends of a copper sample result reported by Wang et al, [9]. From the intensities of the signals identified, it can be seen that in the case of the $\mathrm{Cu} / \mathrm{Al}_{2} \mathrm{O}_{3}$, there are better dispersed $\mathrm{Cu}$ (II) small clusters at the surface than within the bulk, while for the $\mathrm{Cu} / \mathrm{SiO}_{2}$, the reverse is observed, although this difference is not so significant. The redox properties of a metal- support system is known to be normally influenced by the support. The smaller copper clusters have also been reported to reduce more easily than the larger ones [20].

\section{CO adsorption}

Characterisation of the surface coverage of metal atoms or molecules with the use of infra-red spectroscopy of probe molecules such as $\mathrm{CO}$ is a well-established technique [23, 24]. Carbon monoxide was used as a probe molecule to monitor potential geometric and/or electronic effects of its bonding modes on the metal surface.

\section{CO adsorption on copper catalysts}

Figure 7 shows the infrared spectra of $\mathrm{CO}$ adsorbed on $1 \mathrm{wt} \% \mathrm{Cu} / \mathrm{SiO}_{2}$ pre-treated by reducing in hydrogen. A band centred at $2098 \mathrm{~cm}^{-1}$ is present at lower pressure of $\mathrm{CO}$. With increasing pressures of $\mathrm{CO}$, this band shifts to higher wave number $\left(2103 \mathrm{~cm}^{-1}\right.$ at $\left.80 \mathrm{torr}\right)$. Evacuating the $\mathrm{CO}$ in the system reduces the intensity of the band and broadens it but the position remains unchanged. This indicates a contribution of the intensity to have been from gaseous $\mathrm{CO}$. Also, at increased pressure of $\mathrm{CO}$, a very weak shoulder appeared at $2114 \mathrm{~cm}^{-1}$. These bands correspond to linear $\mathrm{M}-\mathrm{CO}$ vibrations as reported by Pritchard et al, [25] on $\mathrm{Cu}$ ions. At the same time, another very low intensity band developed at $2067 \mathrm{~cm}^{-1}$ which disappeared on evacuation of CO. This signal was also observed by Chesters et al. [26] at $2071 \mathrm{~cm}^{-}$ ${ }^{1}$ who assigned to linear $\mathrm{CO}$ adsorption on exposed $\mathrm{Cu}(111)$ and $\mathrm{Cu}(100)$ planes.
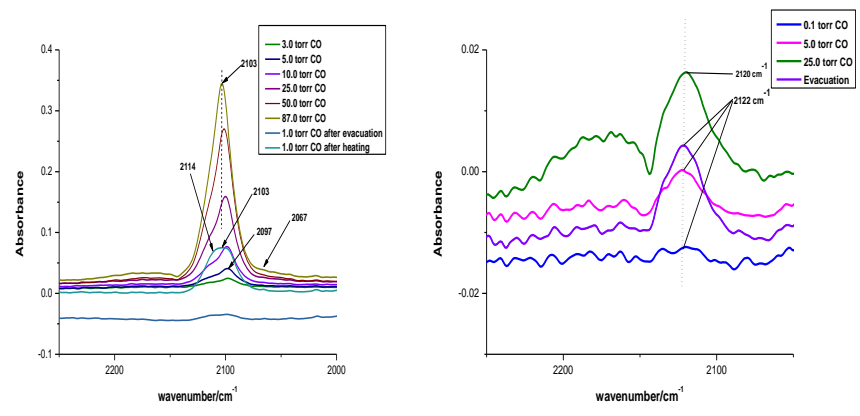

Figure 7: $\mathrm{CO}$ adsorption on $1 \mathrm{wt} \% \mathrm{Cu} / \mathrm{SiO}_{2}$ (a) after reduction in $\mathrm{H}_{2}$ at different pressures of $\mathrm{CO}$ and (b) after in-situ calcination at different pressure of $\mathrm{CO}$

For the in situ calcined sample of the same catalyst, adsorption of $\mathrm{CO}$ is less facile thus less intense bands are observed (Figure 7) for the silica and alumina supported copper samples respectively. Adsorption increased with increasing pressures of $\mathrm{CO}$ from 0.1 to 25.0 torr evidenced by the evolution of a band at $2120 \mathrm{~cm}^{-1}$ with a blue shift to $2122 \mathrm{~cm}^{-1}$ as the pressure increases. This band overlaps with the gaseous $\mathrm{CO}$ doublet but on evacuating, it shows the clear band without the gaseous CO. This band is typical for high index copper planes [27] and highly dispersed copper [27, 28]. This has also been reported to originate from adsorption on bulk $\mathrm{CuO}$ [29] and oxide supported copper [28, 30-38].

The $1 \mathrm{wt} \% \mathrm{Cu} / \mathrm{Al}_{2} \mathrm{O}_{3}$ pre-treated in situ by calcination followed by exposure to $\mathrm{CO}$ showed very little adsorption at $2123 \mathrm{~cm}^{-1}$ on increasing the CO pressure which is typical of oxidised copper species on the surface of the sample. Increasing the pressure of the $\mathrm{CO}$ led to the observation of the gaseous $\mathrm{CO}$ doublet bands (Figure 8). 


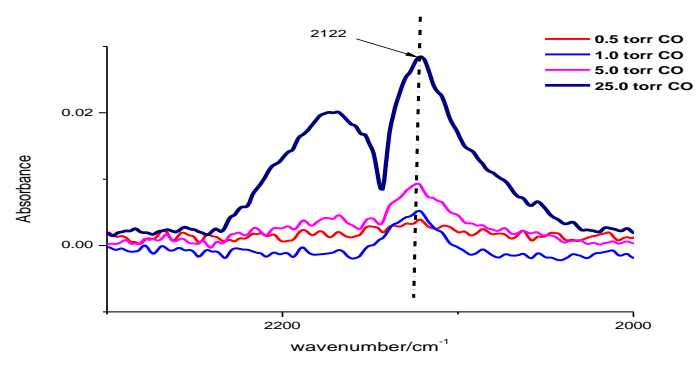

Figure 8: $\mathrm{CO}$ adsorption on $1 w t \% C u / \mathrm{Al}_{2} \mathrm{O}_{3}$ after in-situ reduction at different pressure of $\mathrm{CO}$

\section{Catalyst Activity}

\section{Influence of temperature on Yield of products on the copper catalysts}

Here the copper shows a higher yield of the target formaldehyde on the alumina-supported catalyst, which is at the lower temperature region.
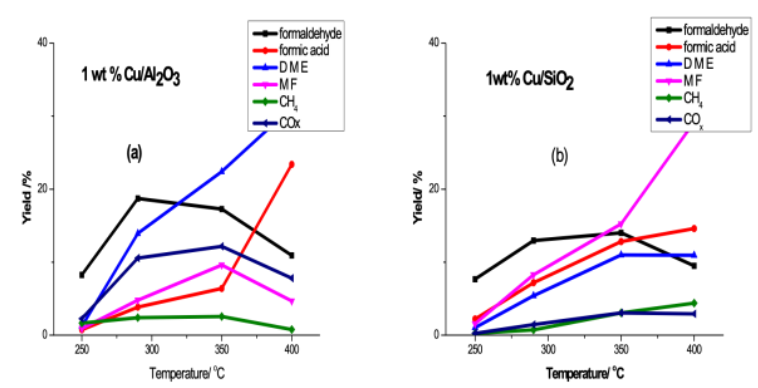

Figure 9: Influence of temperature of products yield on (a) the alumina supported and (b) the silica supported copper catalysts

The alumina supported copper yields high DME at the higher temperature regions while the silica shows higher yield for methyl formate. The alumina-supported sample also shows higher yield of the COx.

\section{Oxidation reactions over $1 \mathrm{wt} \% \mathrm{Cu} / \mathrm{Al}_{2} \mathrm{O}_{3}$}

The conversion of methanol over $1 \mathrm{wt} \% \mathrm{Cu} / \mathrm{Al}_{2} \mathrm{O}_{3}$ and the selectivity to the various products with varying reaction conditions is as shown in Table 3. While Figure 10 shows $(\boldsymbol{a})$ the yield as a function of the various reaction temperatures and $(\boldsymbol{b})$ the yield as a function of varying contact times.

Table 3: Summary of the conversions and selectivities on the $1 \mathrm{wt} \% \mathrm{Cu} / \mathrm{Al}_{2} \mathrm{O}_{3}$ catalyst at $0.22 \mathrm{~s}$

\begin{tabular}{|c|c|c|c|c|c|c|c|}
\hline & & Formaldehyde & $\begin{array}{c}\text { Formic } \\
\text { acid }\end{array}$ & DME & MF & $\mathrm{CH}_{4}$ & Cox \\
\hline$\underset{\mathbf{C}}{\operatorname{Temp}}{ }^{\circ}$ & $\begin{array}{c}\text { Conv/ } \\
\%\end{array}$ & Sel./\% & Sel./\% & $\begin{array}{c}\text { Sel./ } \\
\%\end{array}$ & $\begin{array}{c}\text { Sel./ } \\
\%\end{array}$ & Sel. $/ \%$ & $\begin{array}{c}\text { Sel./ } \\
\%\end{array}$ \\
\hline 250 & 15 & 48 & 5 & 20 & 6 & 11 & 2 \\
\hline 290 & 48 & 39 & 8 & 29 & 10 & 5 & 22 \\
\hline 350 & 64 & 27 & 10 & 35 & 15 & 4 & 19 \\
\hline 400 & 78 & 14 & 30 & 40 & 6 & 1 & 10 \\
\hline
\end{tabular}

It can be seen that with increasing temperature from $250{ }^{\circ} \mathrm{C}$ to $290{ }^{\circ} \mathrm{C}$, there is an increase in yield of formaldehyde but further increase in temperature reduces the yield. Obviously, the trend for the selectivity in Table 3 shows a continuous decrease in the selectivity. But since the conversion increases with temperature an optimum yield for the formaldehyde is observed at $290{ }^{\circ} \mathrm{C}$, but with increasing contact time, the yield is highest at $0.22 \mathrm{~s}$ and levels out through to $2.2 \mathrm{~s}$. a similar trend was observed for 
the methane where the selectivity reduces with increasing temperature and with very low and almost stable yield with both contact time and temperature but with temperature having an increasing effect on the methane yield than the contact time. Formic acid has an opposite trend of selectivity from formaldehyde; it increases from $5 \%$ at $250{ }^{\circ} \mathrm{C}$ to $30 \%$ at $400{ }^{\circ} \mathrm{C}$ while the yield increases with temperature Figure 4 but yields more with temperature increase as compared to contact time. For the DME, the selectivity trend shows an increase with increasing temperature and this is same for the yield with increase in both temperature and contact time. Selectivities for methyl formate and the COx increase with temperature but reduce at $400{ }^{\circ} \mathrm{C}$ and the trend is same for the yields with both temperature and contact time increase.
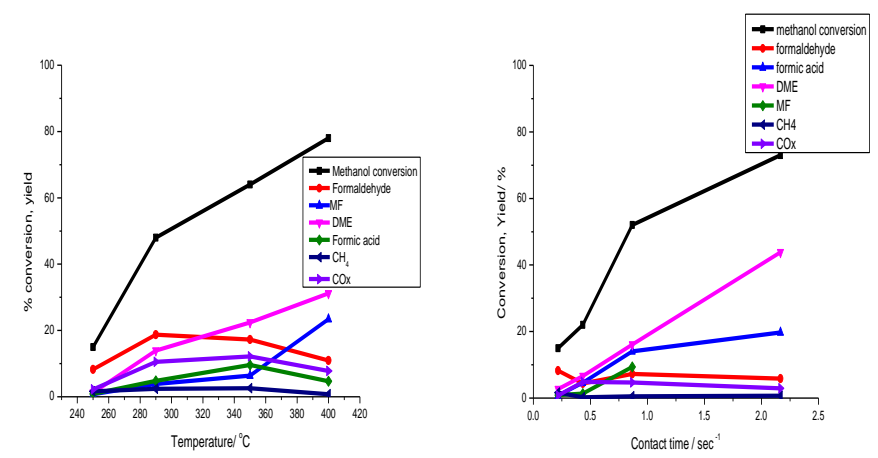

Figure 10: Yield of the various products of methanol oxidation over $1 \mathrm{wt} \% \mathrm{Cu} / \mathrm{Al}_{2} \mathrm{O}_{3}$ with varying temperatures at (a) residence time $=0.22 \mathrm{~s}$ and (b) at $250{ }^{\circ} \mathrm{C}$ and varying contact times

\section{Oxidation reactions with $1 \mathrm{wt} \% \mathrm{Cu} / \mathrm{SiO}_{2}$}

For the $1 \mathrm{wt} \% \mathrm{Cu} / \mathrm{SiO}_{2}$ catalyst Table 4, the conversion ranged 13 to $73 \%$ between 250 and $400{ }^{\circ} \mathrm{C}$ respectively being lower in all temperatures when compared to the copper supported alumina catalyst. Selectivity to formaldehyde was of the same trend, reducing over increasing temperature while the formic acid had an almost stable selectivity of $\sim 20 \%$ over the temperature range with DME increasing from $8 \%$ at $250{ }^{\circ} \mathrm{C}$ to $\sim 15 \%$ over the higher temperatures, methyl formate increasing from $12-40 \%$ over the temperature range with methane and $\mathrm{COx}$ being low at $\sim 5 \%$ at the higher temperatures and $2 \%$ at $250{ }^{\circ} \mathrm{C}$ for methane.

Table 4: Summary of the conversions and selectivities and yields on the $1 \mathrm{wt} \% \mathrm{Cu} / \mathrm{SiO}_{2}$ catalysts at GHSV $=16,615$

\begin{tabular}{|c|c|c|c|c|c|c|c|}
\hline & & $\begin{array}{c}\text { Formalde } \\
\text { hyde }\end{array}$ & $\begin{array}{c}\text { Formic } \\
\text { acid }\end{array}$ & $\begin{array}{c}\text { DM } \\
\mathbf{E}\end{array}$ & MF & $\mathbf{C H}_{4}$ & COx \\
\hline Temp $/{ }^{\circ} \mathrm{C}$ & $\begin{array}{c}\text { Conv/ } \\
\%\end{array}$ & Sel/\% & $\begin{array}{c}\text { Sel./ } \\
\%\end{array}$ & $\begin{array}{l}\text { Sel. } \\
1 \%\end{array}$ & $\begin{array}{l}\text { Sel. } \\
1 \%\end{array}$ & $\begin{array}{l}\text { Sel. } \\
1 \%\end{array}$ & $\begin{array}{l}\text { Sel. } \\
1 \%\end{array}$ \\
\hline 250 & 13 & 59 & 18 & 8 & 12 & 2 & 3 \\
\hline 290 & 36 & 36 & 20 & 15 & 23 & 2 & 4 \\
\hline 350 & 61 & 23 & 21 & 18 & 25 & 5 & 5 \\
\hline 400 & 73 & 13 & 20 & 15 & 40 & 6 & 4 \\
\hline
\end{tabular}

The yield as shown in Figure 11 for formaldehyde in the case of the copper silica catalysts was highest of all products being 8,13 and $14 \%$ at 250,290 and $350{ }^{\circ} \mathrm{C}$ respectively but decreases at higher temperatures to $9 \%$ at $400{ }^{\circ} \mathrm{C}$. All the other products increased in yield with increasing temperature with methyl formate having the highest yield of $29 \%$ at $400{ }^{\circ} \mathrm{C}$. 

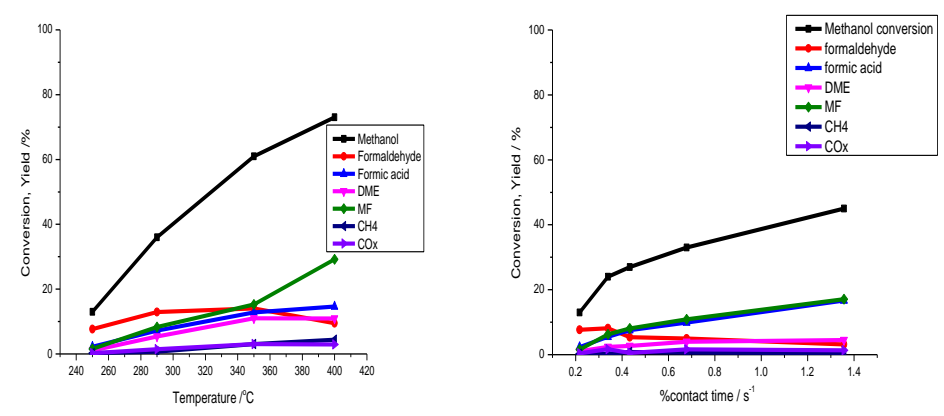

Figure 11: Yield of the various products of methanol oxidation over $1 \mathrm{wt} \% \mathrm{Cu} / \mathrm{SiO}_{2}$ with varying temperatures at (a) residence time $=0.22 \mathrm{~s}$ and (b) at $250{ }^{\circ} \mathrm{C}$ and varying contact times

For the yields of products as a function of varying contact times, formaldehyde decreases with increase in contact time while all the other products followed the same trend opposite to formaldehyde. Methyl formate and formic acid competitively increase in yield with increasing contact time.

\section{Discussion}

In the development of catalysts for catalytic reactions, understanding their nature as synthesised and their likely nature under reaction conditions is of grave importance. The target catalysts in this research of the oxidation of methanol were supported copper catalysts.

\section{Nature of the catalysts}

The nature in terms of electronic and chemical states and the dispersion of the loaded component of a supported catalyst are factors that could contribute to the activity of these catalysts. Information about these could give insight into the performance or behaviour of the catalyst. As the catalysts employed in this research were supported and their preparation could yield agglomerated and/or well-dispersed catalytic systems, they were thus characterised and found to be well-dispersed. This is a positive attribute since well-dispersed supported catalysts are required to be in a way that reactant molecules can interact more effectively with the active catalyst materials and it is known that smaller particles of the active phase of the catalysts are known to maximise the use of the metal through maximising the surface area $[39,40]$.

From their XRD patterns, these metal particles can be deduced to exist as well-dispersed crystallites with no copper metal agglomeration. The results showed no crystalline phases of the loaded metals since these metal particles were small and well dispersed on their various supports. The alumina supported catalysts showed patterns that were typical of the gamma-alumina phases with no reflections corresponding to those of either of the loaded metals. Lippits et al.[41] attributed this non-detection of the loaded metals to being consequent to the metal particulates having small sizes, while other studies have reported that the amount of copper that could reach these particulate size limits for diffraction as being approximately $4 \%$ by weight of $\mathrm{Cu}$ for every $100 \mathrm{~m}^{2} \mathrm{~g}^{-1}$ surface area of $\mathrm{Al}_{2} \mathrm{O}_{3}$ in the case of alumina supported copper catalysts $[42,43]$. For the catalysts used here, their $1 \mathrm{wt} \%$ loadings (in the case of the copper for instance) was well below this limit considering an alumina support of $105 \mathrm{~m}^{2} \mathrm{~g}^{-1}$ and a metal loading of 1 wt $\%$. Nitrogen adsorption studies show the presence of these small particulates loaded as the pure supports showed a slight reduction in the surface area when loaded with the catalyst. Silica with a surface area, about two and a half times that of alumina might be envisaged to show similar or even better dispersion of the supported metals, if the extent of metal precursor-support interactions is not considered.

Following calcination at $400{ }^{\circ} \mathrm{C}$, these samples showed the presence of only few agglomerated metal/metal oxide clusters as suggested by their TPR profiles where the intensities of peaks indicative of the smaller or well-dispersed clusters were higher than those of peaks attributed to larger clusters. This deduction is made on the basis that small particles reduction is identified by their lower temperature reduction peaks as compared to the very low intensity peaks of the larger clusters which occur at a higher reduction temperature as speculated in the literature [43]. These larger peaks which have been proposed to originate form reduction of the small particulates on the support are thus assumed to correspond to higher consumption of the reducing gas (hydrogen), while the peaks assumed to be due to larger clusters were smaller in size and intensity as shown by the peaks at higher reduction temperatures the copper catalyst 
had peaks centred around 267 and a shoulder at $297{ }^{\circ} \mathrm{C}$ were attributed to highly dispersed $\mathrm{Cu}$ clustered species whilst the $297{ }^{\circ} \mathrm{C}$ shoulder is attributed to reduction of $\mathrm{Cu}$ species contained within slightly larger three-dimensional clusters, while a very weak feature at $717^{\circ} \mathrm{C}$ will thus be indicative of larger clusters which may as well be as a result of the metal-support interaction, causing reduction to be harder, so taking place at higher temperatures. The sizes of these peaks were also a direct reflection of their corresponding amount of hydrogen consumed, and this could be seen to indicate greater presence of the smaller clusters of the loaded metals which reduced at lower temperatures as reported. A trend in the reduction profiles on these supported materials was that the silica supported samples also showed more facile reduction as compared to their alumina supported analogue. This could be as a result of the metal support effect, where alumina shows a greater metal-support interaction with most metals and their precursors than silica as widely reported in the literature $[16,19,44-46]$. Thus, metal oxides on the alumina will ordinarily be expected to reduce at higher temperatures compared to the silica supported ones. However, the copper silica samples reduced at slightly higher temperatures when compared to the alumina ones.

Characterisation by $\mathrm{CO}$ adsorption showed intense bands for the $\mathrm{CO}$ adsorbed on well-dispersed clusters of the metals. For instance, the band at $2120 \mathrm{~cm}^{-1}$ observed for copper catalysts has been thought to be due to dispersed copper [27, 28].

Product distribution showed initially highest selectivity to DME (46\%) after which a transition occurred to give predominantly highest selectivity to formaldehyde (58\%). All of the other products also show some variation at inception but then became constant with time on stream.

From the data presented from the characterisation, it was evident that catalyst samples after calcination were oxidised but it is also evident that they got reduced under reaction condition with the action of the methanol, thus producing the partial oxidation products like formaldehyde.

Copper has affinity for atomic oxygen species which cause dissociative adsorption of methanol for the oxidation reactions. Copper is metallic in character owing to its high reactivity. This attribute can however, be detected only under reaction conditions (reduction action of the reactant methanol), so were not detected in the characterisation of the catalyst materials which showed only the presence of oxides of $\mathrm{Cu}$, which are believed to contain the sites responsible for deep oxidation in this reaction [47] However, results from the catalyst test reactions show production of partial oxidation products at steady state.

This route which is known from the general reaction scheme (refer to

Introduction) of methanol oxidation to form formaldehyde could also decompose to form $\mathrm{CO}_{\mathrm{x}}$ and $\mathrm{H}_{2}$ or hydrogenate to form formic acid, although the sites responsible for this was not determined by characterisation. Since the available $\mathrm{O}$ atoms in the system could be in active competition with other species to be scavenged for other processes as shown in all the reaction schemes for the process, gaseous methanol will normally be in excess compared to oxygen, under the conditions of operation here.

\section{Key features of the reaction}

From the product distribution on these catalysts, formaldehyde showed a higher yield at temperatures up to $350{ }^{\circ} \mathrm{C}$ then declines (Figure 9) for the alumina catalyst while the reverse was the case at the highest temperature The silica supported catalysts had the same trend but the conversions were comparatively lower than the alumina ones having the higher selectivity.

The $\mathrm{Cu} / \mathrm{SiO}_{2}(73 \%)$ and $\mathrm{Cu} / \mathrm{Al}_{2} \mathrm{O}_{3}(81 \%)$, as can be seen in the reactivity results (Table 4) where the selectivity to formaldehyde was highest for the silica supported catalysts reaction at $250^{\circ} \mathrm{C}$, lest for the alumina supported ones that showed lower selectivity. These highest selectivities however, took place where conversions were generally lower at the lowest temperature $\left(250{ }^{\circ} \mathrm{C}\right)$ and lower contact time $(0.22 \mathrm{~s})$. Conversion on all the silica supported catalysts was generally lower than for the alumina ones.

Oxi-dehydrogenation

$$
\mathrm{CH}_{3} \mathrm{OH}+0.5 \mathrm{O}_{2} \rightarrow \mathrm{CH}_{2} \mathrm{O}+\mathrm{H}_{2} \mathrm{O}
$$

Dehydrogenation

$$
\mathrm{CH}_{3} \mathrm{OH} \rightarrow \mathrm{CH}_{2} \mathrm{O}+\mathrm{H}_{2} \text {. }
$$

The supports materials also showed marked effects from the products formed, such as in the case of the alumina which is known to be a good catalyst for the dehydration of methanol to DME, and this is reflected in the products formed from samples supported on alumina. At higher conversion consequent to increase in temperature, the copper 
catalysts selectivities of DME increased while with contact time and temperature. For the silica supported samples, methyl formate (MF) formation increased with higher conversion consequent to increase in temperature and contact time on the copper catalysts. This observation is quite unexpected as high selectivity to DME is normally expected at lower conversion of methanol as the route for the production of DME requires the abundance of gaseous methanol and this has been reported to take place at low temperatures and lower conversion. At higher conversion of methanol (i.e. at higher temperature and lower space velocity) there was high selectivity for DME. Fisher and Bell [48] had reported similar formation of DME at higher temperature in a methanol oxidation reaction. Also, the DME formation mechanism which involves an adsorbed surface methoxy group derived from methanol adsorption reacts with another adsorbed methanol molecule to form dimethyl ether. This, however, cannot be said with certainty. Schauermann et al. [49] have also reported desorption of methanol at high temperature as being related to methanol preferentially adsorbing at defect sites on an alumina support. From catalyst test result of this work, it was shown that methanol and methoxy groups coexist on the surface of the catalysts during methanol adsorption experiments. This subject can be explained where the surface of the alumina supported catalysts contain both the Lewis and Brønsted acid sites and it is reported that $\mathrm{Br} \varnothing n$ sted acid sites on $\gamma-\mathrm{Al}_{2} \mathrm{O}_{3}$ are able to catalyse the dehydration of methanol [50, 51].

DME and methyl formate from proposed reaction schemes of this reaction will require molecular methanol to react with methoxy and formate intermediates, respectively, were formed at higher conversion and from the methanol adsorption experiments; bands due to methanol adsorbed on the supports employed in this work were identified. Although these adsorption experiments were not performed at these higher temperatures, it can be assumed that these supports acted in such cases in parallel for the formation of those products. Chantaravitoon et al. [52] have reported less than $40 \%$ of the methanol dehydrated in a methanol dehydration reaction (between 270 and $620{ }^{\circ} \mathrm{C}$ ) gives rise to dimethyl ether, showing the possibility of this as it appears to be observed in this work. The high selectivity to methyl formate; $40 \%$ also prominent on the silica supported catalysts may be in line with what has been suggested by Millar et al. [32] and Monti et al. [53] that methyl formate is formed via the interaction of adsorbed methoxy species and formaldehyde species.

\section{Key features of the mechanism}

Copper [54, 55] has the capability to adsorb methanol dissociatively only in the presence of adsorbed oxygen atoms. The formate and methoxy species formed, adsorb on the surfaces of these metals, where the formate adsorbs after the loss of two $\mathrm{H}$ atoms from the methanol molecule on two adjacent metal sites while the methoxy does the same in a monodentate form by the loss of one $\mathrm{H}$ atom from the methanol molecule (Figure 1).

The above description forms the basis of mechanisms proposed by many for the methanol oxidation reaction, which show two pathways; methoxy and formate, leading to the formation of the various possible products. $[7,56]$;

$$
\begin{aligned}
& \mathrm{CH}_{3} \mathrm{OH}_{a d}+\mathrm{O}_{\text {ad }} \rightarrow \mathrm{CH}_{3} \mathrm{Oad}+\mathrm{OH}_{\text {ad }} \text { (methoxy route) } \ldots \ldots \text { (a) } \\
& \mathrm{CH}_{3} \mathrm{O}_{a d}+\mathrm{O}_{\text {ad }} \rightarrow \mathrm{HCOO}_{\text {ad }}+2 \mathrm{H}_{\text {ad }} \text { (formate route) } \ldots \ldots \text { (b) }
\end{aligned}
$$

The different adsorption sites assumed to be present for these catalysts are associated with the partially reduced oxides of the metals (in the presence of reactants) characterized as prepared by the TPR data that showed the presence of highly dispersed $\mathrm{Cu}$ (II), $\mathrm{CuO}$, clusters which were also confirmed in the CO adsorption results. This is further supported by the reactivity of the catalysts with the methanol forming the various products which all have their various pathways defined by the relative proportions in relation to the selectivity between partial and total oxidation products.

Pre-adsorbed oxygen atoms on the oxides of copper enhances the formation of a methoxy species intermediate which could further dehydrogenate to form formaldehyde or a further oxidation giving rise to the formate intermediate that yields other further products as represented in the mechanisms proposed in the literature. It is however, not straightforward to distinguish the oxidative-dehydrogenation and the direct dehydrogenation processes which require different sites which are characterized by acidic adsorbed oxygen on the copper metal [54, 57-59] or more basic oxygen sites implying weaker and/or stronger bonds with the copper/silver on the catalyst and/or different reaction conditions as these different adsorbed oxygen atoms operate better at different reaction parameters of temperature range;

The specific oxygen involved in the reactions could not be identified in this work through characterisation, making it more ambiguous to ascertain the types involved in any specific route claimed to be taking place. From the products and literature reports of the trends in formation of these products assumptions were made [60]. IR spectroscopy can give insight into the nature and types of adsorbed species that are present on the 
surface of these materials used in the oxidation of methanol. From these experiments' formation of methoxy and formate on the copper surfaces which have been reported by other researches [48, 60-64] were assumed during methanol oxidation on these catalysts.

This could be argued further with the generally low yields of the $\mathrm{CO}_{\mathrm{x}}$ in all the reaction profiles, implying the absence of further oxidation of the formate to $\mathrm{CO}_{\mathrm{x}}$ but rather to formic acid, since the yield of formic acid increased at higher degrees of conversion.

With this, it can be seen that the reaction takes place in the transitional kinetic controlled range at the lower temperatures, demonstrated low contact time that showed basically similar activity of the reaction. These copper catalysts were very active at the initial stage. Reactions taking place where there is extremely low conversion at the lowest temperature $\left(250{ }^{\circ} \mathrm{C}\right)$ and at the very short contact time that favours the partial oxidation with high selectivity to formaldehyde [61]. Also, at this lowest temperature, increasing the conversion by increasing the contact time did not favour the production of formaldehyde as shown in the case of $\mathrm{Cu} / \mathrm{SiO}_{2}$. This can be supported by the observation that the higher temperature dynamics of the reaction system influenced the lower amount of the formaldehyde and higher amounts of the side products formed equally. This implies that the major or primary reaction process and the side reactions are equally influenced by contact time and temperature. This decrease in the formaldehyde yield can be caused by enhanced participation of the methoxy intermediates in the other consecutive reactions where the methoxy rather undergoes further oxidation to the formate which was the case in some of the profiles (e.g. high formation of the formic acid at high conversion through both temperature and contact time increase) shown, as reflected in the product distribution. From the observed trends, a model for the reaction under study drawn out is in agreement with already existing models for the oxi-dehydrogenation pathway (Figure 12)for the reactions that have taken place where the target formaldehyde is selective at the temperature boundaries of the oxidehydrogenation region [64], while the alumina supported catalysts simultaneously dehydrate, the silica promote the methoxy route that favours the formation of methyl formate as a result of the methoxy reaction with formaldehyde desorbed. The only striking thing observed is that at these wide parameters of investigation, there was little formation of the $\mathrm{CO}_{\mathrm{x}}$.

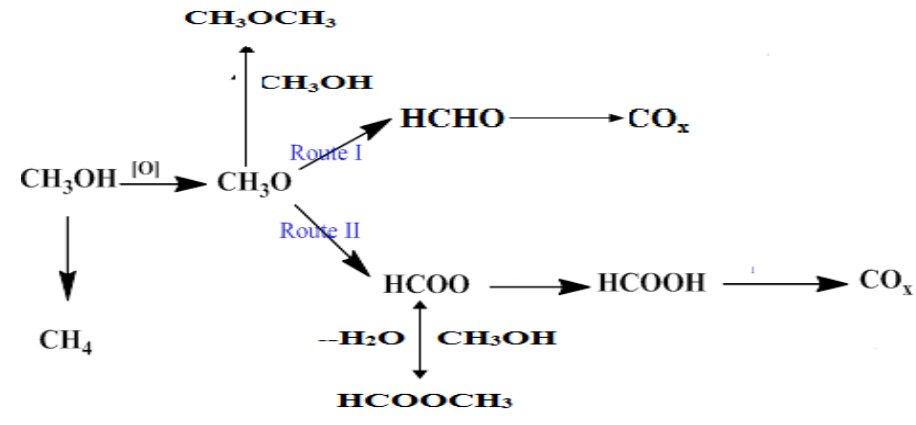

Figure 12: Schematic representation of the proposed reaction process for methanol oxidation and the various steps that were enhanced by the different sample catalysts.

The scheme represented above (Figure 12) is proposed considering the formation of the various products under the varied conditions of temperature and contact time. The primary product was considered mainly to be formaldehyde and proceeded through the Route I. Route II which is meant to be an alternative route to Route I, however yielded products that could be related to a different reaction pathway required for this route. These are deemed so, considering that for an initial increase in temperature (from $250-290{ }^{\circ} \mathrm{C}$ ) for instance favoured the formation of formaldehyde which eventually reduced and formation of the other products (secondary) were subequently seen for all the catalysts. At the highest temperature however, a reverse in trend was the case where the formation of the secondary products dominated;

\section{Conclusion}

The oxi-dehydrogenation route for the oxidation of methanol over synthesised and characterised supported copper catalyst reported to be an exothermic reaction, giving rise to formaldehyde and other products of DME, Formic acid and MF and $\mathrm{COx}$ the reactions considering the temperature range of operation and the concurrent formation of products that are reported for the oxidehydrogenation route. Formation of the various products from variations in temperature and space velocity/contact time were investigated and also conformed to these assumptions and a scheme was proposed.

Characterisation of these materials through nitrogen and $\mathrm{CO}$ adsorption studies showed metal oxides on the supports while XRD and TPR studies provided evidence that the materials had been produced with good dispersion. The TPR results also showed the existence of the reduction peaks for the copper present.

Generally, the supports showed a very marked effect on the selectivities of the products where the alumina based samples were very selective to DME while the silica ones were selective to methyl 
formate. Methanol adsorption studies on the surface of these materials revealed the existence of the adsorbed species which may have been involved in product formed.

\section{Acknowledgement}

TETFund Nigeria and the College of Physical Sciences, University of Aberdeen are gratefully acknowledged.

\section{References}

[1] Arends, I. W. C. E., Sheldon RA (2010) Modern Oxidation Methods, 2nd Ed. (Ed.: J. E.

Bäckvall):147 - 185.

[2] Vinod CP, Wilson K, Lee AF (2011) Recent advances in the heterogeneously catalysed aerobic selective oxidation of alcohols. J Chem Technol Biotechnol 86:161.

[3] Yilmaz AH, Atalay FS, Atalay S (2005) Catalytic Oxidation of Methanol to Formaldehyde. NATO science series:345.

[4] Machiels CJ, Sleight AW (1982) Kinetic isotope effect in the selective oxidation of methanol to formaldehyde over some molybdate catalysts. J Catal 76:238-239.

[5] Wachs IE, Saleh RY, Chan SS, Chersich CC (1985). Appl Catal 15:339.

[6] W.H. Cheng, U. Chowdhry, A. Ferretti, L.E. Firment, R.P. Groff, C.J. Machiels, E.M. McCarron, F. Ohuchi, R.H. Staley and A.W. Sleight, in: Heterogeneous Catalysis, ed. B.L. Shapiro (University Press, Texas A\&M, 1984).

[7] Butlerow A (1985) On some derivatives of methylene iodide. Annals of Chemistry and Pharmacy 111:242 - 252.

[8] Wang Z, Liu Q, Yu J, Wu T, Wang G (2003) Surface structure and catalytic behavior of silicasupported copper catalysts prepared by impregnation and sol-gel methods. Appl catal A: Gen 239:87-94.

[9] B. Delmon, P. Grange, P.A. Jacobs and G. Poncelet, Preparation of Catalysts II (Amsterdam, Elsevier, 1979).

[10] IUPAC (1995) Manual of methods and procedures for catalyst characterization (Technical Report). Pure \& Appl Chem 67:1257-1306.
[11] Kaichev VV, Popova GY, Chesalov YA, Saraev AA, Zemlyanov DY, Beloshapkin SA, Knop-Gericke A, Schlögl R, Andrushkevich TV, Bukhtiyarov VI (2014) Selective oxidation of methanol to form dimethoxymethane and methyl formate over a monolayer $\mathrm{V}_{2} \mathrm{O}_{5} / \mathrm{TiO}_{2}$ catalyst. $\mathrm{J}$ Catal 311:59-70.

[12] S.J. Greg and K.S.W. Sing, Adsorption, Surface Area and Porosity (London, Academic Press, 1991).

[13] Gaudet J (2010) Gas-Phase Epoxidation of Ethylene and Propylene. PhD Thesis submitted to the faculty of Virginia Polytechnic Institute and state university: 10 .

[14] Thomas C (2011) Should W Surface Density of WOx $-\mathrm{ZrO}_{2}$ Catalysts Be Calculated with Respect to the Specific Surface Area of the Sample or That of $\mathrm{ZrO}_{2}$ only? J Phy Chem C 115:2253.

[15] Luo Y, Hao J, Hou Z, Fu L, Li R, Ning P, Zheng $X$ (2004) Influence of preparation methods on selective catalytic reduction of nitric oxides by propene over silver-alumina catalyst. Catal Today 93-95:797-803.

[16] Poulston S, Parlett PM, Stone P, Bowker M (1996) Surface oxidation and reduction of $\mathrm{CuO}$ and $\mathrm{Cu}_{2} \mathrm{O}$ studied using XPS and XAES. Surf Interface Anal 24:811-820.

[17] Zhang S, Huang W, Qiu X, Li B, Zheng X, Wu $S$ (2001) Comparative Study on Catalytic Properties for Low-Temperature $\mathrm{CO}$ Oxidation of $\mathrm{Cu} / \mathrm{CeO}_{2}$ and $\mathrm{CuO} / \mathrm{CeO}_{2}$ Prepared via Solvated Metal Atom Impregnation and Conventional Impregnation. Catal Lett 80:41.

[18] Martínez-Arias A, Fernández-García M, Gálvez O, Coronado JM, Anderson JA, Conesa JC, Soria J, Munuera G (2000) Comparative study on redox properties and catalytic behavior for $\mathrm{CO}$ oxidation of $\mathrm{CuO} / \mathrm{CeO}_{2}$ and $\mathrm{CuO} / \mathrm{ZrCeO}_{4}$ catalysts. J Catal 195:207-216.

[19] Moretti E, Lenarda M, Storaro L, Talon A, Montanari T, Busca G, Rodríguez-Castellón E, Jiménez-López A, Turco M, Bagnasco G, Frattini R (2008) One-step synthesis of a structurally organized mesoporous $\mathrm{CuO}-\mathrm{CeO}_{2}-\mathrm{Al}_{2} \mathrm{O}_{3}$ system for the preferential CO oxidation. Appl Catal A: Gen 335:46-55.

[20] Dow WP, Wang YP, Huang TJ (1996) Yttriastabilized zirconia supported copper oxide catalyst: 
I. Effect of oxygen vacancy of support on copper oxide reduction. J Catal 160:155-170.

[21] Severino F, Brito J, Carías O, Laine J (1986) Comparative study of alumina-supported $\mathrm{CuO}$ and $\mathrm{CuCr}_{2} \mathrm{O}_{4}$ as catalysts for $\mathrm{CO}$ oxidation. $\mathrm{J}$ Catal 102:172-179.

[22] Zecchina A, Scarano D, Bordiga S, Spoto G, Lamberti C (2001) Surface structures of oxides and halides and their relationships to catalytic properties. Adv Catal 46:265-397.

[23] Gribov EN, Zavorotynska O, Agostini G, Vitillo JG, Ricchiardi G, Spoto G, Zecchina A (2010) FTIR spectroscopy and thermodynamics of $\mathrm{CO}$ and $\mathrm{H}_{2}$ adsorbed on $\gamma$-, $\delta$-and $\alpha-\mathrm{Al}_{2} \mathrm{O}_{3}$. Phys Chem Chem Phys 12:6474-6482.

[24] Pritchard J, Catterick T, Gupta RK (1975) Infrared spectroscopy of chemisorbed carbon monoxide on copper. Surf Sci 53:1-20.

[25] Chesters MA, Parker SF, Raval R (1986) Fourier transform reflection-absorption infrared spectroscopy of adsorbates on $\mathrm{Cu}(100)$ and $\mathrm{Cu}$ (111). Surf Sci 165:179-190.

[26] Hollins P (1992) The influence of surface defects on the infrared spectra of adsorbed species. Surface Science Reports 16:51-94.

[27] Balkenende AR, van der Grift CJG, Meulenkamp EA, Geus JW (1993) Characterization of the surface of a $\mathrm{Cu} / \mathrm{SiO}_{2}$ catalyst exposed to $\mathrm{NO}$ and $\mathrm{CO}$ using IR spectroscopy. Appl Surf Sci 68:161-171.

[28] Busca G (1987). J Mol Catal:225.

[29] Davydov A (1994). Russ J Phys Chem 68:2045.

[30] Amara M, Gengembre L, Olivier D (1988) Preparation of monovalent copper by a single electron transfer step in the photoreduction of zinc oxide-supported copper catalysts. Appl Catal 41:147-164.

[31] Millar GJ, Rochester CH, Waugh KC (1991) Infrared Study of the Adsorption of Formic Acid on Silica-supported Copper and Oxidised Copper Catalysts. J Chem Soc Faraday Trans, 87:14911496.

[32] Dandekar A, Vannice MA (1998)

Determination of the Dispersion and Surface
Oxidation States of Supported Cu Catalysts. J Catal 178:621-639.

[33] Hadjiivanov K, Kantcheva M, Klissurski D (1996) IR study of CO adsorption on Cu-ZSM-5 and $\mathrm{CuO} / \mathrm{SiO}_{2}$, catalysts: $\mathrm{CF}$ and $\mathrm{n}$ : components of the $\mathrm{Cu}^{+}-\mathrm{CO}$ bond. J Chem Soc Faraday Trans 92:4595.

[34] Waqif M, Lakhdar M, Saur O, Lavalley J (1994) FTIR study of the influence of sulfate species on the adsorption of $\mathrm{NO}, \mathrm{CO}$ and $\mathrm{NH}_{3}$ on $\mathrm{CuO} / \mathrm{Al}_{2} \mathrm{O}_{3}$ catalysts. J Chem Soc, Faraday Trans 90:2815.

[35] Amores JMG, Escribano V, S., Busca G, Lorenzelli V (1994) Solid-state and surface chemistry of $\mathrm{CuO}-\mathrm{TiO}_{2}$ (anatase) powders. J Mater Chem 4:965-971.

[36] Kantcheva MM, Hadjiivanov KI, Davydov AA, Budneva AA (1992) Low-temperature CO adsorption on $\mathrm{Cu}^{2+} / \mathrm{TiO}_{2}$ catalysts. Appl Surf Sci 55:49-55.

[37] Clarke DB, Suzuki I, Bell AT (1993) An Infrared Study of the Interactions of $\mathrm{CO}$ and $\mathrm{CO}_{2}$ with $\mathrm{Cu} / \mathrm{SiO}_{2}$. J Catal 142:27-36.

[38] Sinfelt JH (1972) Highly dispersed catalytic materials. Annu Rev of Mater Sci 2:641.

[39] Wang H, Yi C, Tian L, Wang W, Fang J, Zhao J, Shen W (2012) Ag-Cu Bimetallic Nanoparticles Prepared by Microemulsion Method as Catalyst for Epoxidation of Styrene. Journal of Nanomaterials $8: 1$.

[40] Lippits MJ, Boer Iwema RRH, Nieuwenhuys BE (2009) A comparative study of oxidation of methanol on $-\mathrm{Al}_{2} \mathrm{O}_{3}$ supported group IB metal catalysts. Catal Today 145:27-33.

[41] Strohmeier BR, Levden DE, Field RS, Hercules DM (1985) Surface spectroscopic characterization of $\mathrm{CuAl}_{2} \mathrm{O}_{3}$ catalysts. J Catal 94:514-530.

[42] Friedman RM, Freeman JJ, Lytle FW (1978) Characterization of $\mathrm{CuAl}_{2} \mathrm{O}_{3}$ catalysts. J Catal 55:10-28.

[43] Bogdanchikova N, Meunier FC, Avalos-Borja M, Breen JP, Pestryakov A (2002) On the nature of the silver phases of $\mathrm{Ag} / \mathrm{Al}_{2} \mathrm{O}_{3}$ catalysts for reactions involving nitric oxide. Appl Catal B 36:287-297. 
[44] Seker E, Cavataio J, Gulari E, Lorpongpaiboon $P$, Osuwan S (1999) Nitric oxide reduction by propene over silver/alumina and silvergold/alumina catalysts: effect of preparation methods. Appl catal A: Gen 183:121-134.

[45] Nakatsuji T, Yasukawa R, Tabata K, Ueda K, Niwa M (1998) Catalytic reduction system of NOx in exhaust gases from diesel engines with secondary fuel injection. Appl Catal B Env 17:333-345.

[46] Alejo L, Lago R, Peña MA, Fierro JLG (1997) Partial oxidation of methanol to produce hydrogen over $\mathrm{Cu} \square \mathrm{Zn}$-based catalysts. Appl catal A: Gen 162:281-297.

[47] Fisher IA, Bell AT (1999) A Mechanistic Study of Methanol Decomposition over $\mathrm{Cu} / \mathrm{SiO} 2$, $\mathrm{ZrO}_{2} / \mathrm{SiO}_{2}$, and $\mathrm{Cu} / \mathrm{ZrO}_{2} / \mathrm{SiO}_{2}$. J Catal 184:357-376.

[48] Schauermann S, Hoffmann J, Joha'nek V, Hartmann J, Libuda J (2002) Adsorption, decomposition and oxidation of methanol on alumina supported palladium particles. Phys Chem Chem Phys, 4:3909.

[49] Campelo JM, Garcia A, Herencia JF, Luna D, Marinas JM, Romero AA (1995) Conversion of Alcohols ( $\alpha$-Methylated Series) on $\mathrm{ALPO}_{4}$ Catalysts. Journal of Catalysis 151:307-314.

[50] Yaripour F, Baghaei F, Schmidt I, Perregaard J (2005) Catalytic dehydration of methanol to dimethyl ether (DME) over solid-acid catalysts. Catal Commun 6:147-152.

[51] Chantaravitoon P, Chavadej S, Schwank J (2004) Temperature-programmed desorption of methanol and oxidation of methanol on Pt-Sn $/ \mathrm{Al}_{2} \mathrm{O}_{3}$ catalysts. Chem Eng J 97:161-171.

[52] Monti DM, Can't NW, Trimm DL, Wainwright MS (1986) Hydrogenolysis of methyl formate over copper on silica. I. Study of surface species by in situ infrared spectroscopy. J Catal 100:17-27.

[53] Sexton BA, Hughes AE, Avery NR (1985) A spectroscopic study of the adsorption and reactions of methanol, formaldehyde and methyl formate on clean and oxygenated $\mathrm{Cu}$ (110) surfaces. Surf Sci 155:366-386.

[54] Wachs I, Madix RJ (1979) The oxidation of formaldehyde on a copper (110) surface. Surf Sci $84: 375$

[55] Barnes CJ, Pudney PDA, Guo Q, Bowker M (1990) Molecular-beam Studies of Methanol Partial
Oxidation on $\mathrm{Cu}(110)$. J Chem SOC, Faraday Trans I 86:2693.

[56] Tatibouet JM, Germain JE, Volta JC (1983). J Catal 82:240.

[57] Bowker M, Madix RJ (1981) XPS, UPS and thermal desorption studies of the reactions of formaldehyde and formic acid with the $\mathrm{Cu}(110)$ surface. Surf Sci 102:542-565.

[58] Francis SM, Leibsle FM, Haq S, Xiang N, Bowker M (1994) Methanol oxidation on $\mathrm{Cu}$ (110). Surf Sci 315:184.

[59] Carley AF, Owens AW, Rajumon MK, Roberts MW, Jackson SD (1996). Catal Lett 37:79.

[60] Andersson, A., Holmberg, J. \& Häggblad, R. (2016) Process Improvements in Methanol Oxidation to Formaldehyde: Application and Catalyst Development. Top Catal 59:1589-1599.

[61] Poulston S, Rowbotham E, Stone P, Parlett P, Bowker M (1998) Temperature-programmed desorption studies of methanol and formic acid decomposition on copper oxide surfaces. Catal Lett 52:63-67.

[62] Clarke DB, Lee DK, Sandoval MJ, Bell AT (1994) Infrared Studies of the Mechanism of Methanol Decomposition on $\mathrm{Cu} / \mathrm{SiO}_{2}$. J Catal 150:81-93.

[63] Bazilio CA, Thomas WJ, Ullah U, Hayes KE (1985) The Catalytic Oxidation of Methanol. Proc R Soc Lond A 399:181.

[64] Zuo Z, Wang L, Han P, Huang W (2014) Insights into the reaction mechanisms of methanol decomposition, methanol oxidation and steam reforming of methanol on $\mathrm{Cu}$ (111): A density functional theory study. Int J Hydrogen Energy 39:1664-1679. 